\title{
Spatial and temporal variability of air quality in Shanghai in 2015
}

\author{
Li Liu, Lihuan He, Yu Bai, Mi Zhou, Fengying Zhang, Yirui Wu, Guowei Gao and Yang Yu
}

1China National Environmental Monitoring Center, Beijing 100012

\begin{abstract}
In order to understand the temporal-spatial patterns of air pollutants in Shanghai, the concentrations of six air pollutants $\left(\mathrm{SO}_{2}, \mathrm{NO}_{2}, \mathrm{PM}_{10}, \mathrm{PM}_{2.5}, \mathrm{CO}, \mathrm{O}_{3}\right)$ and air quality index (AQI) were analyzed. The results showed that, the percentage of excellent/good-AQI days was $70.7 \%$ during the whole year of 2015, and $\mathrm{PM}_{2.5}, \mathrm{O}_{3}$ and $\mathrm{NO}_{2}$ were the main air pollutants in Shanghai. Besides, the air quality in winter was most serious, followed by that in spring and autumn, and the air quality in summer was the best. From the perspective of spatial distribution, monitoring stations in YangpuSipiao and Putuo which were located in the urban area were affected by traditional industries and the air quality were poor, while those in Chuansha and Zhangjiang of Pudong which were located on the edge of the city showed relatively good air quality.
\end{abstract}

\section{Introduction}

For a better understanding on the mechanism of atmospheric pollution in China, it is indispensable to study the temporal and spatial differences of atmospheric pollution in typical cities. Therefore, this article took Shanghai, where is of high intensity of human disturbance and has the background of rapid urbanization, as the research area. We conducted the research based on the atmospheric environment monitoring data which were collected following the new "Ambient Air Quality Standard" (GB3095-2012) in Shanghai in 2015. In total, six kinds of major air pollutants and air quality index (AQI) derived from ten automatic monitoring control points of environmental air quality in Shanghai were analyzed. The dominant air pollutants in Shanghai, their seasonal changes, change patterns, and spatial differentiation were evaluated and discussed. This research can provide the necessary reference for the public to be aware of the air quality in Shanghai and for the government to develop the air pollution control strategy.

\section{Methodology}

\subsection{Overview of the study area}

Shanghai $\left(120^{\circ} 52^{\prime} \sim 122^{\circ} 12^{\prime} \mathrm{E}, 30^{\circ} 40^{\prime} \sim 31^{\circ} 53^{\prime} \mathrm{N}\right)$ is located in the east of the East China Sea, south to Hangzhou Bay, adjacent to Jiangsu and Zhejiang provinces, and located in the front of the Alluvial plain of the Yangtze River Delta. The terrain is flat, with an average altitude of $4 \mathrm{~m}$. The climate in Shanghai is subtropical humid monsoon climate.

\subsection{Data sources and processing}

Daily air quality monitoring data were provided by Shanghai Environmental Monitoring Center and China National Environmental Monitoring Center. Daily $\mathrm{PM}_{2.5}$, $\mathrm{CO}, \mathrm{NO}_{2}, \mathrm{SO}_{2}$, and $\mathrm{PM}_{10}$ concentrations were derived from the average of available hourly data measured at 9 state-controlled monitoring stations across Shanghai. Daily concentration of $\mathrm{O}_{3}$ was calculated as daily maximum 8-hour average values of $\mathrm{O}_{3}$ concentrations. Locations of the monitoring stations are presented in Fig.1. According to Technical Regulation for Ambient Air Quality Assessment (on trial) (HJ 663-2013), when calculating daily means of air pollutants in a city, at least $75 \%$ hourly concentrations from the monitoring stations of the city should be available in a single day. If more than $25 \%$ of the data in a monitoring station are missing in the whole study period, the entire station would be excluded. According to technical guidelines of Chinese government, these locations must not be in the immediate vicinity of traffic intersections or major industrial polluters and should be sufficiently distant from any other emission sources. Thus, the monitoring data we used could reflect the general background urban air pollution level in our study area.

\footnotetext{
${ }^{1}$ corresponding author:yuyang@enemc.cn
} 


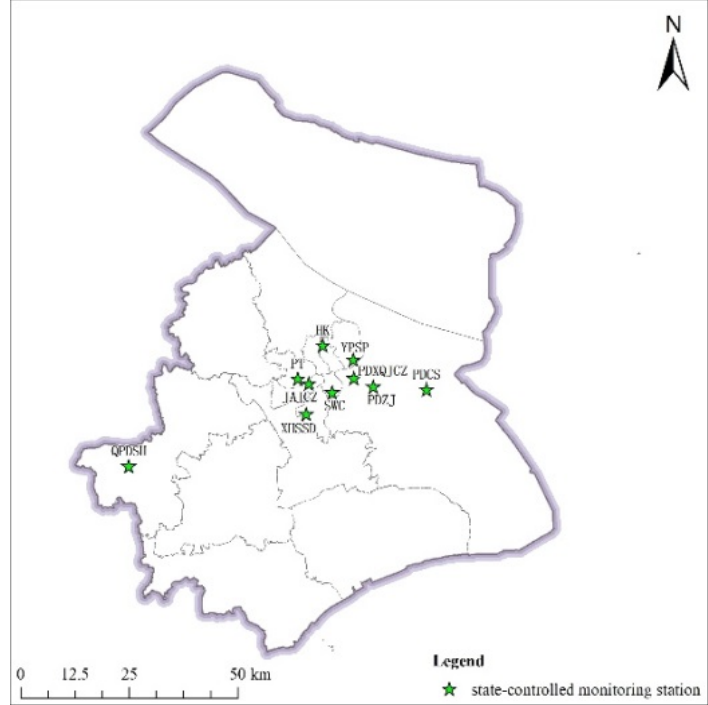

Fig.1 Spatial distribution of state-controlled monitoring stations

\section{Results and discussion}

\subsection{General air quality of Shanghai}

According to Technical Regulation for Ambient Air Quality Assessment (on trial) (HJ 663-2013), in 2015, there were 258 days when air quality index (AQI) was excellent or good, which was one day less than in 2014. The annual rate of excellent/good-AQI days was $70.7 \%$, which was 6.3 percentage points lower than in 2014 .
Among the 365 days, there were 55 days with good AQI; 203 days with moderate AQI; 73 days when AQI denoted light pollution; 26 days when AQI denoted medial pollution; and 8 days when AQI denoted heavy pollution.

In 2015, the average concentration of PM2.5 in Shanghai was $53 \mu \mathrm{g} / \mathrm{m}^{3}, 18 \mu \mathrm{g} / \mathrm{m}^{3}$ higher than that provided for in the National Second Ambient Air Quality Standards (NSAAQS). The annual average concentration of PM10 in Shanghai was $69 \mu \mathrm{g} / \mathrm{m}^{3}$, meeting the NSAAQS. The annual average concentration of $\mathrm{SO}_{2}$ in Shanghai was $17 \mu \mathrm{g} / \mathrm{m}^{3}$, conforming to the NFAAQS. The annual average concentration of NO2 in Shanghai was $46 \mu \mathrm{g} / \mathrm{m}^{3}, 6 \mu \mathrm{g} / \mathrm{m} 3$ higher than that of NSAAQS recommended. The average concentration of ozone in Shanghai, which was the ninetieth percentile monitored daily in the eight peak hours, was $161 \mu \mathrm{g} / \mathrm{m} 3,1 \mu \mathrm{g} / \mathrm{m} 3$ higher than what NSAAQS required. Daily average concentration of $\mathrm{CO}$ monitored in Shanghai varied between $0.4 \mathrm{mg} / \mathrm{m}^{3}$ and $2.2 \mathrm{mg} / \mathrm{m}^{3}$, meeting NSAAQS.

$\mathrm{PM}_{2.5}$ was the main air pollutant in Shanghai, with 116 days as the primary air pollutants; followed by $\mathrm{O}_{3}$ and $\mathrm{NO}_{2}$ (Figure 2). $\mathrm{PM}_{2.5}$ was the main air pollutant in Spring and winter, which had highest number of days as primary pollutant. $\mathrm{O}_{3}$ was the main primary pollutant in Summer, as the temperature rises, and the light is sufficient. In addition, the frequency of $\mathrm{NO}_{2}$ as the primary pollutant accounted for a certain proportion in each month, but less than that of the other two pollutants, and the peak value appeared in November.

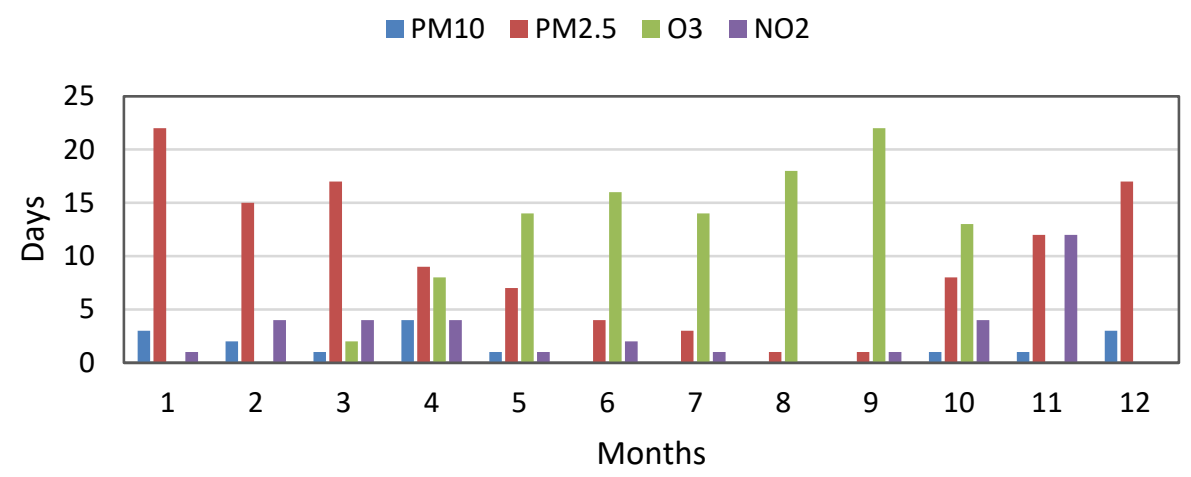

Fig.2 The monthly changes on days of primary pollutant in Shanghai during 2015

Further analyses showed that there was a certain correlation among the six air pollutants in Shanghai (Table 1). There were significantly positive correlations between $\mathrm{CO}, \mathrm{NO}_{2}, \mathrm{SO}_{2}, \mathrm{PM}_{2.5}$, and $\mathrm{PM}_{10}(\mathrm{p}<0.05)$, which showed a strong root homology. $\mathrm{O}_{3}$ was significantly negatively correlated with other atmospheric pollutants. The photochemical reactions among primary pollutants such as $\mathrm{SO}_{2}, \mathrm{CO}, \mathrm{NOx}$, and volatile organic compounds (VOCs) discharged into the air by the combustion of fossil fuels and factories take place under the action of light, and then produced secondary pollutants such as $\mathrm{O}_{3}$.

Table.1 Correlation between six major air pollutants in Shanghai

\begin{tabular}{lllllll}
\hline & $\mathrm{CO}$ & $\mathrm{NO}_{2}$ & $\mathrm{O}_{3}$ & $\mathrm{SO}_{2}$ & $\mathrm{PM}_{2.5}$ & $\mathbf{P M}_{10}$ \\
\hline $\mathrm{CO}$ & 1.00 & & & & & \\
$\mathrm{NO}_{2}$ & $0.78^{* *}$ & 1.00 & & & & \\
\hline
\end{tabular}




\begin{tabular}{lllllll}
\hline $\mathbf{O}_{3}$ & $-0.42 * *$ & $-0.40^{* *}$ & 1.00 & & & \\
$\mathbf{S O}_{2}$ & $0.77 * *$ & $\mathbf{0 . 7 8 * *}$ & $\mathbf{- 0 . 3 4 * *}$ & 1.00 & & \\
$\mathbf{P M}_{2.5}$ & $\mathbf{0 . 9 0 * *}$ & $0.76^{* *}$ & $-0.26^{* *}$ & $0.80^{* *}$ & 1.00 & \\
$\mathbf{P M}_{10}$ & $0.81 * *$ & $0.74 * *$ & $-0.19 * *$ & $\mathbf{0 . 8 3 * *}$ & $\mathbf{0 . 9 2 * *}$ & 1.00 \\
\hline
\end{tabular}

The highest AQI was in January, mainly due to the increased traffic and energy consumption and

\subsection{Daily change trends}

The results showed that the air quality of Shanghai showed obvious seasonal variation characteristics, with the most serious air pollution in winter, followed by spring and autumn, and the best was in summer.

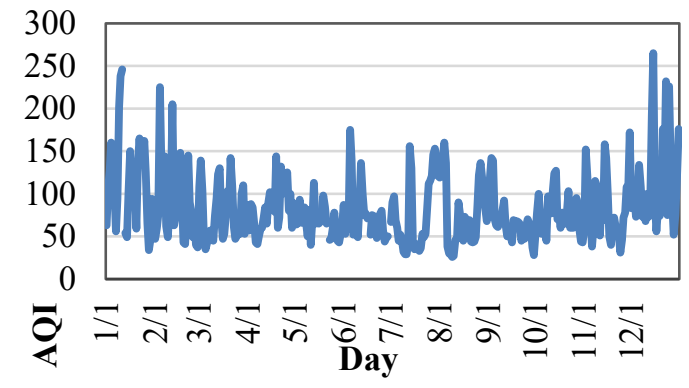
surrounding cities during the Spring Festival travel rush, the lack of rainfall, low wind speed and low temperature in winter in Shanghai. The stable atmosphere, the tendency of temperature inversion, and the insignificant air convection led to the difficulty of pollutant diffusion. In August, there was a small peak of AQI, which was mainly affected by high temperature, long sunshine duration and high intensity, and the large amount of $\mathrm{O}_{3}$ resulted in from it. The air quality in September was the best.

\subsection{Spatial distribution of air pollutants}

In order to determine the spatial differences of pollutants, the annual average concentrations of air pollutants at each station were calculated (Fig.5).

Fig.3 Daily variation of AQI in Shanghai

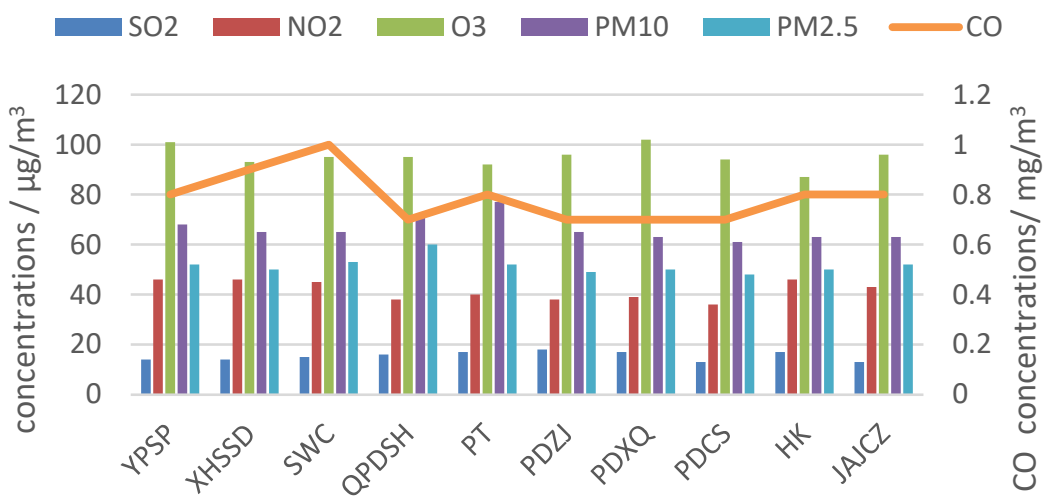

Fig.4 Spatial variation of six major pollutants in Shanghai Generally speaking, the concentrations of $\mathrm{PM}_{2.5}$ and $\mathrm{PM}_{10}$ were relatively high in all stations, and the lowest value of $\mathrm{PM}_{2.5} / \mathrm{PM}_{10}$ appears in the district of Putuo(PT). The $\mathrm{PM}_{10}$ concentration distribution of this station was significantly different from that of other stations. It was indicated that this station was mainly affected by $\mathrm{PM}_{10}$, which may be due to the large traffic flow and high exhaust emissions around it. In comparison, Yangpusipiao (YPSP) monitoring station, which also had poor air quality, with a larger $\mathrm{PM}_{2.5} / \mathrm{PM}_{10}$ value and a lower $\mathrm{PM}_{10}$ concentration, but higher $\mathrm{NO}_{2}$ and $\mathrm{O}_{3}$ concentrations, which may be due to the serious fossil fuel combustion and photochemical pollution. Jing'an monitoring station(JAJCZ) with good air quality had the highest $\mathrm{PM}_{2.5} / \mathrm{PM}_{10}$ value and high $\mathrm{O}_{3}$ concentration, which was mainly affected by secondary pollutants produced by photochemical reaction. Xuhuishangshida(XHSSD), and Shiwuchang(SWC) had the highest $\mathrm{CO}$ concentration, which was mainly because of inadequate fossil fuel combustion. Compared with the other three stations, the $\mathrm{CO}$ concentration of the monitoring station in Pudongxinqu(PDXQ) was low, but the $\mathrm{O}_{3}$ concentration was significantly high. The three stations with the best air quality, Hongkou(HK), Pudongchuansha(PDCS) and PudongZhangjiang(PDZJ), had lower concentrations of pollutants, mainly due to their location on the edge of the city, high open terrain, high wind speed, and short pollutant accumulation time.

\section{Conclusion}

Clarifying the distribution characteristics and formation mechanism of major atmospheric pollutants in typical cities provides a new way of thinking for the study of ecological environmental problems brought by urbanization. It has important practical significance for the realization of regional sustainable development. In this study, the air quality of Shanghai in 2015 was analyzed, and the temporal-spatial characteristics of air pollutants was discussed. The results showed that, the 
annual rate of excellent/good-AQI days was $70.7 \%$ in 2015, $\mathrm{PM}_{2.5}, \mathrm{O}_{3}$ and $\mathrm{NO}_{2}$ were the main air pollutants in Shanghai. The most serious air quality was in winter, followed by spring and autumn, and the best air quality was in summer. From the perspective of spatial distribution, YangpuSipiao and Putuo stations located in the urban area were affected by traditional industries and the air quality was poor, while Chuansha and Zhangjiang monitoring stations in Pudong were located on the edge of the city and their air quality were relatively good.

\section{References}

1. United Nations. World Urbanization Prospects, The $2014 \quad$ Revision, Highlights. http://www.un.org/en/development/desa/population/t heme/urbanization/index.shtml. 2014

2. Zhang \& Cao. 2015. Fine particulate matter $\left(\mathrm{PM}_{2.5}\right)$ in China at a city level[J]. Scientific Reports.

3. Fang et al. 2015. Estimating the Impact of Urbanization on Air Quality in China Using Spatial Regression Models. Sustainability. 7, 15570-15592.

4. Matus, K.; Nam, K.-M.; Selin, et al. 2012. Health damages from air pollution in China. Glob. Environ. Chang. 22: 55-66 